Original Article

\title{
ASSESSMENT OF LAND - USE CHANGE EFFECTS ON FUTURE BEEKEEPING SUITABILITY VIA CA-MARKOV PREDICTION MODEL
}

\author{
Fatih Sari* \\ Selçuk University, Konya, Turkey \\ *corresponding author: fatihsari@selcuk.edu.tr \\ Received: 23 December 2019; accepted 21 May 2020
}

A bstract

In this study, land- use changes in the Muğla province were determined and future Land Use Cover Change (LUCC) maps were predicted. Because Muğla accounts for $90 \%$ of pine honey production in the world, the study area has vital importance for the Turkish (also for other countries) beekeeping sector and this importance reveals the necessity of both monitoring and predicting the LUCC of Muğla in future. This study demonstrates a combined CA-Markov land use change model and beekeeping suitability analysis via MultiCriteria Decision Analysis (MCDA) to predict the future of beekeeping suitability in Muğla in the Geographical Information Systems (GIS) platform. 2006 and 2012 LUCC maps were used to predict the 2018 LUCC, and transition probabilities between land cover classes were analyzed. A recent 2018 LUCC map was used to demonstrate accuracy analysis of the predicted 2018 LUCC map. Considering the 0.96 Kappa accuracy, a good fit was determined and the CA-Markov model was used to predict the 2025, 2030, 2040 and 2050 LUCC maps. Moreover, using the Analytical Hierarchy Process (AHP), beekeeping suitability assessment was generated. The results indicate that there will be a considerable increase in the urban areas and decrease in grasslands in the future. Related to this, the suitable areas will be decreased by $50 \mathrm{~km}^{2}$ and non-suitable areas will be increased by $76 \mathrm{~km}^{2}$ from 2018 to 2050 . The study simulated the beekeeping suitability to guide beekeepers and local authorities towards a better understanding of the reasons for decreasing suitability and developing urgent land use management systems.

Keywords: beekeeping suitability, CA-Markov land use change model, land use change modeling, Multi-Criteria Decision Analysis

\section{INTRODUCTION}

Land Use Cover Change (LUCC) is one of the main dynamics of environmental modeling and management issues in understanding the reasons for environmental change (Guan et al., 2011). Land- cover changes are caused by either humans (urbanization, agricultural activities, deforestation and industrialization) or natural factors (landslides, forest fires, flood hazards) in the economic, social, environmental, topographic and climatic dimensions (Lambin, 1997; Wang et al., 2012; Halmy et al., 2015). Biodiversity and habitat loss are major causes of land-use change and are revealed by the rate of land-use change (Sala et al., 2000; Halmy et al., 2015).

Biodiversity is vitally important for beekeeping activities, which can be affected by land-use changes easily. The pollination role of beekeeping activities and their economic contribution to rural areas thanks to such derived products as honey, propolis, bee venom, royal jelly and pollen make beekeeping an economic and rural development indicator (Estoque \& Murayama, 2010; 2011; Damián, 2016). Approximately 33\% of agricultural crop pollination is done by honey bees, which represents an invisible economic income due to the increased yield of crops (Maris et al., 2008; Oldroyd \& Nanork, 2009). Declines in honey bee populations place significant stress on global food resources, agricultural activities and ecosystem facilities (Aizen et al., 2009; Vanbergen et al., 2013; Otto et al., 2016). A major reasons for the declines are land-use change (Spivak et al., 2011; Goulson et al., 2015; Otto et al., 2016), land-use change-related habitat fragmentation and limited forage areas which are important for beekeeping activities. Due to 
this importance, sustaining and ensuring productivity require monitoring land-use changes and their effects on beekeeping activities and honey bee colonies.

To detect land-use changes, mathematical models and cellular models have been used (Markov model and cellular automata) (Agarwal et al., 2002; Parker et al., 2003; Subedi et al., 2013). The Markov model is a stochastic model that has been frequently used to reveal the underlying complex reasons for land-use changes describing a sequence of possible events (Muller \& Middleton, 1994; Gagniuc, 2017). The model is used to detect and simulate the LUCC and transition probabilities describing the trends (Baker, 1989; Muller \& Middleton, 1994; Huang et al., 2008; Halmy et al., 2015; Mondal et al., 2016). The Markov model is based on the calculation of a system status from earlier to later with transition probabilities and calculates transitions from all land-use classes to another (Pontius \& Malanson, 2005). The model proposes that a later status of a pixel has a close relationship to its earlier status, which refers to transition probabilities (Mondal et al., 2016). The Markov model is not spatially dependent, which is important for understanding the effects of land-use change (Sklar \& Costanza, 1991; Halmy et al., 2015).

However, beekeeping activities are related to the factors which must be evaluated spatially to reveal the suitability by considering land-use types. This can be achieved by integrating such empirical models as the cellular automata (CA) model and (CA-Markov) to provide a more suitable infrastructure for modeling and predicting land-use changes (Ye \& Bai, 2008; Eastman, 2009; Guan et al., 2011; Halmy et al., 2015). The flexible structure of the CA model makes it possible to integrate it with other models to simulate spatial suitability for beekeeping activities in the future which involve comprehensive and complex processes in predicting land-use changes. While the Markov chain provides temporal change between land-use classes (transition matrix), the CA-Markov model provides spatial changes of land-use classes for considering neighborhood structure by generating transition probability maps (Wu, 2002; Thomas \& Laurence, 2006; He et al., 2008; Guan et al., 2011). The intensive agricultural activities and rich flora of Turkey provide a suitable environment for beekeeping activities. Moreover, $90 \%$ of the total pine honey production in the world is done endemically in the Muğla province, which represents a significant national export (Miguel et al., 2014). The main objective of this study is to predict the future beekeeping suitability of the Muğla province through the determining of land-use changes between 2006 and 2050. Because Muğla has a high tourism potential along with intensive beekeeping activities, beekeeping areas tend to decrease and be surrounded by urban areas. Thus, determining future land-use and predicting beekeeping suitability will reveal the necessary procedures for planners and beekeepers to manage land-use to protect pine honey sources and decide on bee conservation areas. Although this study was implemented only in the Muğla province, the proposed beekeeping suitability model and the CA-Markov model, which is introduced for beekeeping for the first time, make this study a conceptual model for determining future beekeeping suitability to be applied over the whole country.

\section{MATERIAL AND METHOD}

\section{Study Area}

The study агеa, the Muğla province, is an агеa of $12,974 \mathrm{~km}^{2}$ located between $27^{\circ} 13^{\prime} 30^{\prime \prime}$ and $29^{\circ} 41^{\prime} 00^{\prime \prime} \mathrm{W}$ longitude and 36 $16^{\circ} 22^{\prime \prime}$ and $37^{\circ} 35^{\prime} 10^{\prime \prime} \mathrm{N}$ latitude. Muğla is located where the Aegean Sea and Mediterranean Sea meet and has great importance due to pine honey production in its valuable forests. Every year, $9 \%$ of all forest fires in Turkey have occurred in the Muğla province and approximately 500 hectares of forest have been destroyed (URL 1). Additionally, the Muğla province has a high precipitation rate and this leads to flood hazards in several river basins which stretch from the high mountains to the coast. Intensive tourism is another factor that threatens nature in Muğla. In the Muğla province, 15,000 active beekeepers 
are employed every year for pine honey. The Muğla province boundaries are given in Fig. 1.

\section{Spatial Data for LUCC and Beekeeping Suit- ability}

Recent studies on beekeeping suitability, Maris et al., (2008); Estoque \& Murayama, (2010); Amiri \& Shariff, (2012); Abou-Shaara et al., (2013); Camargo et al., (2014); Femandez et al., (2016) and Zoccali et al., (2017) used elevation, slope, aspect, distance to water, distance to roads, pollen-nectar resources and flora criteria to generate beekeeping suitability maps. In this study, elevation, slope, aspect, distance to roads, railways, water surfaces and power lines, land-use and natural hazards criteria were used to generate the beekeeping suitability map.

Slope and aspect data were derived from ASTER GDEM elevation data at a resolution of thirty meters. Physical environmental factors including roads, railways, buildings, settlements and power lines indirectly affect beekeeping activities and are considered in this study. Human-related pollution, air and noise pollution, greenhouse gases, exhaust emissions and intensive traffic flow negatively affect both flora and beekeeping activities. The criteria data were retrieved from the Open Street Map (OSM) database in vector format and converted to buffer zones to determine the effect zones via spatial analysis with ArcGIS 10.5 software. The distance to water resources criterion was included to consider a clean water supply to apiaries. As a new approach, the natural disaster criterion was included in this study to consider flood areas, forest fire zones and landslides to avoid loss of apiaries. For land-use change modeling, 2006, 2012 and 2018 land-use maps were retrieved from CORINE land cover data at a resolution of twenty meters.

\section{LUCC Change Prediction}

The Markov chain model and cellular automata (CA) are discrete dynamic models. However, the Markov chain model does not provide any information about the spatial distribution of occurrences in each category, while CA provides spatial characteristics to the model and determines transition rules from time $t$ to time $t+1$. The Markov chain model determines the transition matrix and the CA-Markov model uses the transition areas table and transition probability images to generate predictions of land-use changes within specified periods. Using a contiguity filter, the CA-Markov can generate geographical land-use changes (Mondal et al., 2016).

The transition probability matrix was calculated for the transitions between 2006 and 2012 to predict the 2018 LUCC map. Each element of the transition probability matrix includes cross tabulation of two images that refer to the probability of transition from one category to another. The LUCC classes were specified according

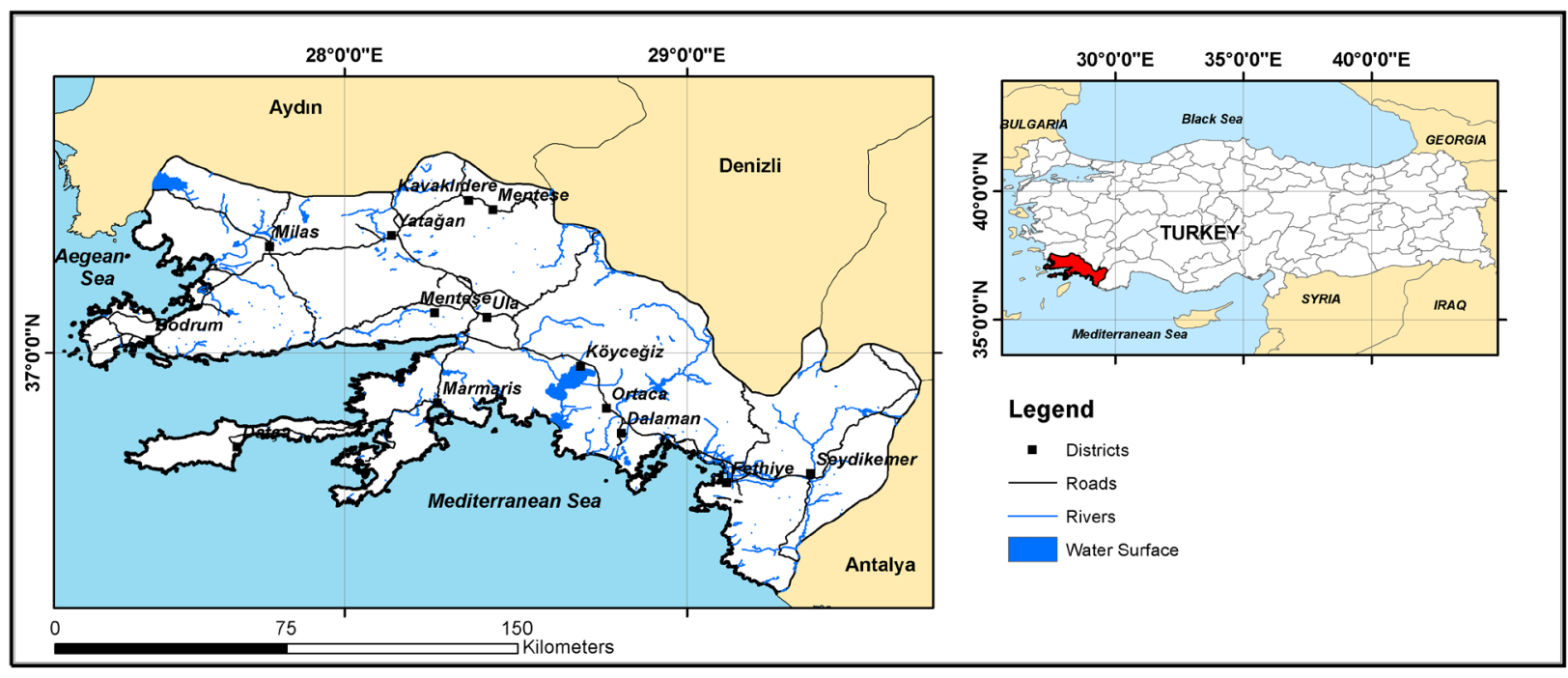

Fig. 1. Muğla Province Boundaries. 
to their importance for beekeeping activities. Urban areas, agricultural lands, grasslands, sclerophyll, forests, sparsely vegetated areas, beaches, forests, fruit tree areas, complex cultivation patterns and water surfaces were specified as LUCC classes for determining the transition probability matrix with IDRISI 17.0 software. In total, eighty-seven transition maps were generated from each LUCC category to another.

\section{Weighting (AHP)}

The Analytic Hierarchy Process (AHP), proposed by Saaty $(1977 ; 1980)$, determines the importance of each criterion with a 1 to 9 preference value scale (1=Equal, 3= Moderately, 5= Strongly, 7=Very, 9=Extremely). AHP calculation starts with a pairwise comparison matrix to compare the importance of each criterion to another (Eq. 1). A normalization matrix is used to determine the weights (Eq. 2), and the weights of each criterion represent the average sum of each criterion (Eq. 3). The consistency of the pairwise comparison matrix must be calculated to decide whether the comparisons of criteria are consistent or not. The consistency index $(\mathrm{Cl})$ is one of the methods used to define the consistency coefficient of the pairwise comparison matrix (Eq. 4). Calculating the consistency index requires the $\lambda$ max (eigenvalue) value and random index (RI) value according to the matrix order (Eq. 5). After the calculation of the $\mathrm{Cl}$ and $\mathrm{Rl}$ values, the consistency ratio (CR) is calculated with Formula 6. If CR exceeds 0.1, based on expert knowledge and experience (Saaty \& Vargas, 1991), a revision of the pairwise comparison matrix with different values is recommended (Saaty, 1980).

\begin{tabular}{c|ccccc} 
A & Criterion 1 & Criterion 2 & Criterion 3 & $\ldots$ & Criterion n \\
\hline Criterion 1 & $a_{11}$ & $a_{12}$ & $a_{13}$ & $\ldots$ & $a_{1 n}$ \\
Criterion 2 & $a_{21}$ & $a_{22}$ & $a_{23}$ & $\ldots$ & $a_{2 n}$ \\
$\ldots$ & $\ldots$ & $\ldots$ & $\ldots$ & $\ldots$ & $\ldots$ \\
Criterion n & $a_{n 1}$ & $a_{n 2}$ & $a_{n 3}$ & $\ldots$ & $a_{n n}$
\end{tabular}

(1)

$$
\begin{aligned}
& a_{i j}^{1}=\frac{a_{i j}}{\sum_{i=1}^{n} a_{i j}} \\
& w_{i}=\left(\frac{1}{n}\right) \sum_{i=1}^{n} a_{i j}^{\prime},(i, j=1,2,3, \ldots, n) \\
& C I=\frac{\lambda_{\max }-n}{n-1}
\end{aligned}
$$

$\lambda_{\text {max }}=\frac{1}{n} \sum_{i=1}^{n}\left[\frac{\sum_{j=1}^{n} a_{i j} w_{j}}{w_{i}}\right]$

$C R=\frac{C I}{R I}$

\section{RESULTS}

\section{Land Use Cover Change}

The LUCC maps from 2006 to 2018 revealed that the LUCC classes of urban areas, water surfaces and fruit tree areas are increasing at an average rate of $20 \%$. The LUCC classes of agriculture and complex cultivation are tending to decrease at an average rate of $25 \%$. These classes have decisive roles in beekeeping suitability and the rate of change reveals important information about beekeeping. However, Muğla's status as the world's leading producer of the pine honey is evidently related to the LUCC class of forests. The forest cover is very dominant in the Muğla province ( 56\% of the total area) and seems stable between 2006 and 2018 with a 1\% rate of increase (Tab. 1).

A comparison of the 2018 LUCC map to the predicted 2018 LUCC map for accuracy analysis showed that the maps are quite similar to each other (Fig. 2). Especially, the predicted Forest (FR), Sparse Vegetation (SV), Agriculture (AG) and Complex Cultivation (CV) LUCC classes are very close to the current 2018 LUCC classes. Land-use change calculations require a transition probability matrix. In this stage, 2006 and 2012 LUCC class transitions were determined to predict the 2018 LUCC map. Each 
Table 1.

Area change of land covers $\left(\mathrm{km}^{2}\right)$ and rates (\%)

\begin{tabular}{ccccccccc}
\hline & \multicolumn{2}{c}{2006} & \multicolumn{2}{c}{2012} & \multicolumn{2}{c}{2018} & \multicolumn{2}{c}{2018 Predicted } \\
\cline { 2 - 8 } & Area & $\%$ & Area & $\%$ & Area & $\%$ & Area & $\%$ \\
\hline Urban (UA) & 298.36 & 2.1 & 352.92 & 2.5 & 357.66 & 2.5 & 379.86 & 2.7 \\
Agriculture (AG) & 779.98 & 5.6 & 641.06 & 4.6 & 629.85 & 4.5 & 626.14 & 4.5 \\
Grasslands (GR) & 310.93 & 2.2 & 427.48 & 3.0 & 396.28 & 2.8 & 425.00 & 3.0 \\
Sclerophyll (SC) & 1447.04 & 10.3 & 1481.95 & 10.5 & 1561.26 & 11.1 & 1474.05 & 10.5 \\
Forests (FR) & 7594.41 & 54.0 & 7884.13 & 56.1 & 7905.13 & 56.2 & 7908.50 & 56.3 \\
Sparse Vegetation (SV) & 723.81 & 5.2 & 326.39 & 2.3 & 317.21 & 2.3 & 322.37 & 2.3 \\
Beaches (BE) & 325.80 & 2.3 & 251.67 & 1.8 & 243.59 & 1.7 & 220.67 & 1.6 \\
Fruit Tree (FT) & 363.94 & 2.6 & 479.49 & 3.4 & 477.25 & 3.4 & 507.84 & 3.6 \\
Complex Cultivation (CC) & 2052.24 & 14.6 & 2036.88 & 14.5 & 1991.78 & 14.2 & 2008.88 & 14.3 \\
Water (WT) & 157.08 & 1.1 & 171.64 & 1.2 & 173.68 & 1.2 & 180.25 & 1.3 \\
\hline
\end{tabular}

diagonal element of the transition probability matrix refers to the probability that the related land cover class did not change from 2006 to 2012. Another element of the transition matrix represents the probability that the related land cover class is joined to another. Besides the LUCC classes change rates, specification of the transition potentials is also important. For instance, the change transition potential maps revealed that urban areas were gained from the complex cultivation LUCC class and that the forest class was gained from agricultural lands. This situation is commonly related to beekeepers who do not produce pine honey. However, the loss and gain rates will be important for future beekeeping suitability map generation.

The transition probability matrix revealed that all the land- cover classes tended to be stable, with 95\% transition probability values. Moreover, beaches tended to be forest areas which had the highest transition probability. Addition- ally, grasslands tended to become urban areas, because urbanization is easier in grasslands than forests, agricultural lands and beaches due to the plain topography of grasslands. Most of the transition probabilities occurred in all classes to urban areas. Because of Muğla's high tourism potential, new tourism centers and buildings were located in other land- cover areas (Tab. 2). Moreover, kappa statistics indicated that the 2018 LUCC and the predicted 2018 LUCC maps have a good fit, with a $97 \%$ overall kappa value. The determined producer and user average accuracy values are higher than $93 \%$ and the best fit was determined for Forest (FR), Agriculture (AG), Complex Cultivation (CC) and Sclerophyll (SC) LUCC classes (over 94\%). The poorest fit (85\%) was determined for Beaches (BE), which are not important for beekeeping. The kappa statistics and producer/user accuracy assessments indicate that the CA-Markov model predicted the 2018 LUCC map successfully and
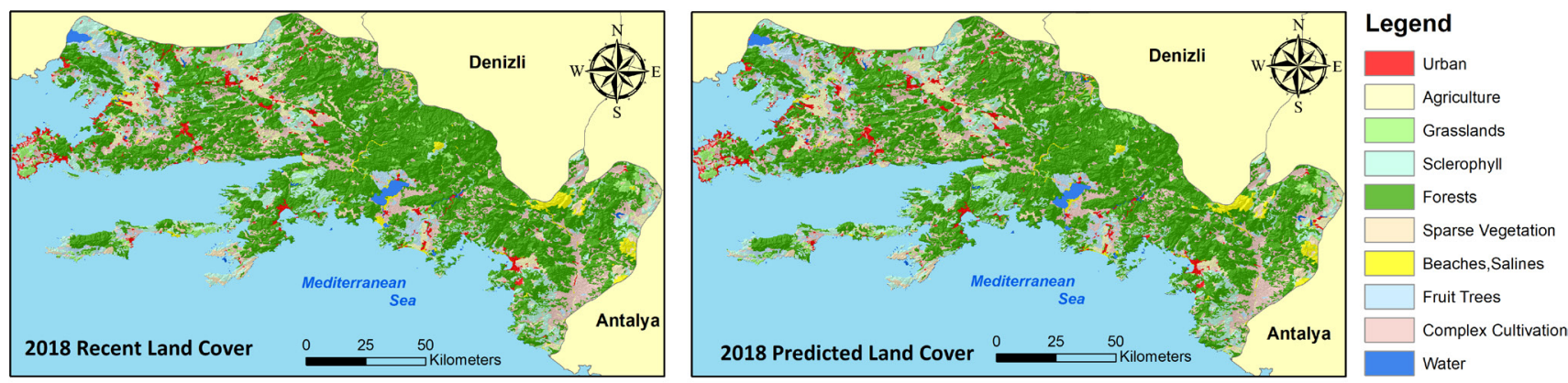

Fig. 2. 2018 LUCC and Predicted 2019 LUCC maps. 
Table 2.

Transition probability matrix from 2006 to 2012

\begin{tabular}{ccccccccccc}
\hline LUCC & UA & AG & GR & SC & FR & SV & BE & FT & CC & WT \\
\hline UA & 0.993 & 0.001 & 0.000 & 0.000 & 0.000 & 0.000 & 0.000 & 0.000 & 0.000 & 0.003 \\
AG & 0.001 & 0.971 & 0.000 & 0.000 & 0.000 & 0.000 & 0.000 & 0.024 & 0.002 & 0.000 \\
GR & 0.008 & 0.001 & 0.974 & 0.000 & 0.013 & 0.000 & 0.000 & 0.000 & 0.001 & 0.000 \\
SC & 0.001 & 0.000 & 0.001 & 0.992 & 0.000 & 0.000 & 0.002 & 0.000 & 0.000 & 0.001 \\
FR & 0.001 & 0.000 & 0.000 & 0.000 & 0.997 & 0.000 & 0.000 & 0.000 & 0.000 & 0.000 \\
SV & 0.001 & 0.000 & 0.000 & 0.000 & 0.005 & 0.984 & 0.006 & 0.000 & 0.000 & 0.002 \\
BE & 0.003 & 0.002 & 0.001 & 0.000 & 0.141 & 0.000 & 0.850 & 0.000 & 0.000 & 0.000 \\
FT & 0.005 & 0.000 & 0.000 & 0.000 & 0.000 & 0.000 & 0.000 & 0.9943 & 0.000 & 0.000 \\
CC & 0.003 & 0.000 & 0.000 & 0.000 & 0.000 & 0.000 & 0.000 & 0.007 & 0.985 & 0.002 \\
WT & 0.000 & 0.000 & 0.000 & 0.000 & 0.000 & 0.000 & 0.000 & 0.000 & 0.000 & 0.991 \\
\hline
\end{tabular}

can be reliably used for predicting future LUCC maps for beekeeping suitability. The statistics are given in Tab. 3.

Using the CA-Markov model, 2025, 2030, 2040 and 2050 LUCC prediction maps were generated to be able to predict future beekeeping suitability. The future LUCC maps are given in Fig. 3.

The predicted LUCC maps show expansion in urban and forest areas. Most of the urban expansion and new urban area constitution occur in coastal zones which have high tourism potential. Urban areas will be increased from 2.9 to $3.7 \%$ between 2018 and 2050. The LUCC maps predict a $0.8 \%$ increase in fruit tree areas and $0.4 \%$ increase in forests. In total, considering the suitable and non-suitable LUCC classes for beekeeping, the non-suitable areas will be increased by $1.5 \%$ and suitable areas by $0.4 \%$. The change rates of the LUCC classes are given in Fig. 4.

When evaluating the change rates of the LUCC classes per year, the complex cultivation class tends to decrease more than the other classes which are important for beekeeping activities. Although forests tend to be enlarged, the annual change rate is decreasing. Grasslands are also

Accuracy assessment of LUCC change model

\begin{tabular}{|c|c|c|c|c|c|c|c|c|c|c|}
\hline \multirow{2}{*}{\multicolumn{3}{|c|}{ Information for Location }} & \multicolumn{8}{|c|}{ Information for Quantity } \\
\hline & & & \multicolumn{2}{|c|}{$\mathrm{No}[\mathrm{n}]$} & \multicolumn{2}{|c|}{ Medium[m] } & \multicolumn{3}{|c|}{ Perfect[p] } & \\
\hline Perfect[P(x)] & \multicolumn{2}{|c|}{$P(n)=$} & \multicolumn{2}{|c|}{0.4417} & \multicolumn{2}{|c|}{0.6737} & \multicolumn{3}{|c|}{1.0000} & \\
\hline PerfectStratum[K(x)] & \multicolumn{2}{|c|}{$K(n)=$} & \multicolumn{2}{|c|}{0.3584} & \multicolumn{2}{|c|}{0.6737} & \multicolumn{3}{|c|}{0.6790} & \\
\hline MediumGrid[M(x)] & \multicolumn{2}{|c|}{$M(n)=$} & \multicolumn{2}{|c|}{0.3584} & \multicolumn{2}{|c|}{0.6531} & \multicolumn{3}{|c|}{0.6790} & \\
\hline MediumStratum[H(x)] & \multicolumn{2}{|c|}{$H(n)=$} & \multicolumn{2}{|c|}{0.0833} & \multicolumn{2}{|c|}{0.1690} & \multicolumn{3}{|c|}{0.2719} & \\
\hline $\mathrm{No}[\mathrm{N}(\mathrm{x})]$ & \multicolumn{2}{|c|}{$N(n)=$} & \multicolumn{2}{|c|}{0.0833} & \multicolumn{2}{|c|}{0.1690} & \multicolumn{3}{|c|}{0.2719} & \\
\hline AgreementChance $=$ & \multicolumn{2}{|c|}{0.0833} & \multicolumn{2}{|c|}{ DisagreeQuantity = } & \multicolumn{2}{|c|}{0.3263} & \multicolumn{3}{|c|}{ Kstandard = } & 0.5825 \\
\hline AgreementQuantity = & \multicolumn{2}{|c|}{0.0856} & \multicolumn{2}{|c|}{ DisagreeStrata = } & \multicolumn{2}{|c|}{0.0000} & \multicolumn{3}{|c|}{ Klocation = } & 0.9592 \\
\hline AgreementStrata = & \multicolumn{2}{|c|}{0.0000} & \multicolumn{2}{|c|}{ DisagreeGridcell = } & & 0206 & & cationSt & ta $=$ & 0.9592 \\
\hline AgreementGridcell = & & & & & & & & Kno $=$ & & 0.6215 \\
\hline & UA & AG & GR & SC & FR & SV & $\mathrm{BE}$ & FT & CC & WT \\
\hline Error of Commission & 0.145 & 0.043 & 0.130 & 0.030 & 0.023 & 0.072 & 0.054 & 0.125 & 0.614 & 0.906 \\
\hline Producer Accuracy & 90.75 & 95.05 & 93.26 & 91.52 & 97.74 & 94.27 & 85.56 & 93.10 & 94.66 & 94.41 \\
\hline User Accuracy & 85.42 & 95.64 & 86.96 & 96.92 & 97.70 & 92.78 & 94.51 & 87.49 & 93.86 & 90.93 \\
\hline Kappa Index & 0.906 & 0.949 & 0.931 & 0.912 & 0.972 & 0.942 & 0.854 & 0.930 & 0.944 & 0.943 \\
\hline Overall Kappa & 0.973 & & & & & & & & & \\
\hline Overall Accuracy & 0.986 & & & & & & & & & \\
\hline
\end{tabular}



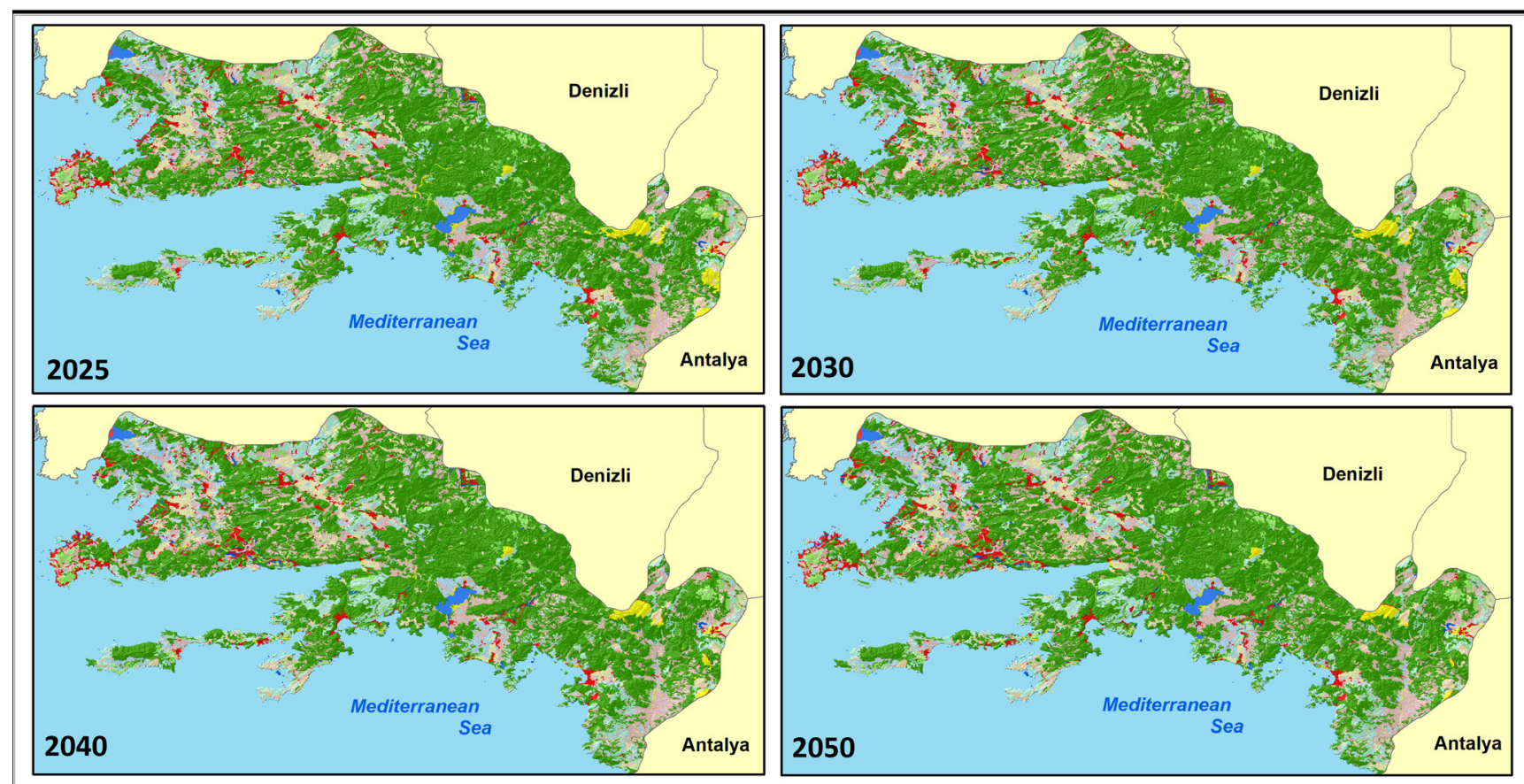

Legend

Urban $\square$ Grasslands $\square$ Forests

Agriculture

Sclerophyll

Sparse Vegetation

Beaches,Salines $\square$ Complex Cultivation

Fruit Trees

Water

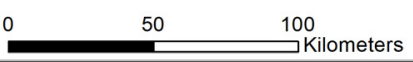

Fig. 3. Predicted 2025, 2030, 2040, 2050 LUCC maps.

important for beekeeping activities, and this class has a decreasing trend. The annual change rates of classes are given in Fig. 5.

\section{Prediction of Beekeeping Suitability}

Beekeeping suitability map generation includes criteria for weight calculation and classification of specified criteria intervals from 1 to 9 according to the beekeeping requirements. The importance of each criterion and preference value of decision matrix were specified by considering the decisions of thirty expert beekeepers located in the study агеa and involved in previous studies in the literature. The weights of each criterion were calculated by using a pairwise comparison matrix. However, the consistency of weight calculation must be evaluated to decide whether the weights are consistent or not. The calculated 0.091 CR value shows that the preference values given in the pairwise comparison matrix are consistent. The preference values and weights are given in Tab. 4.

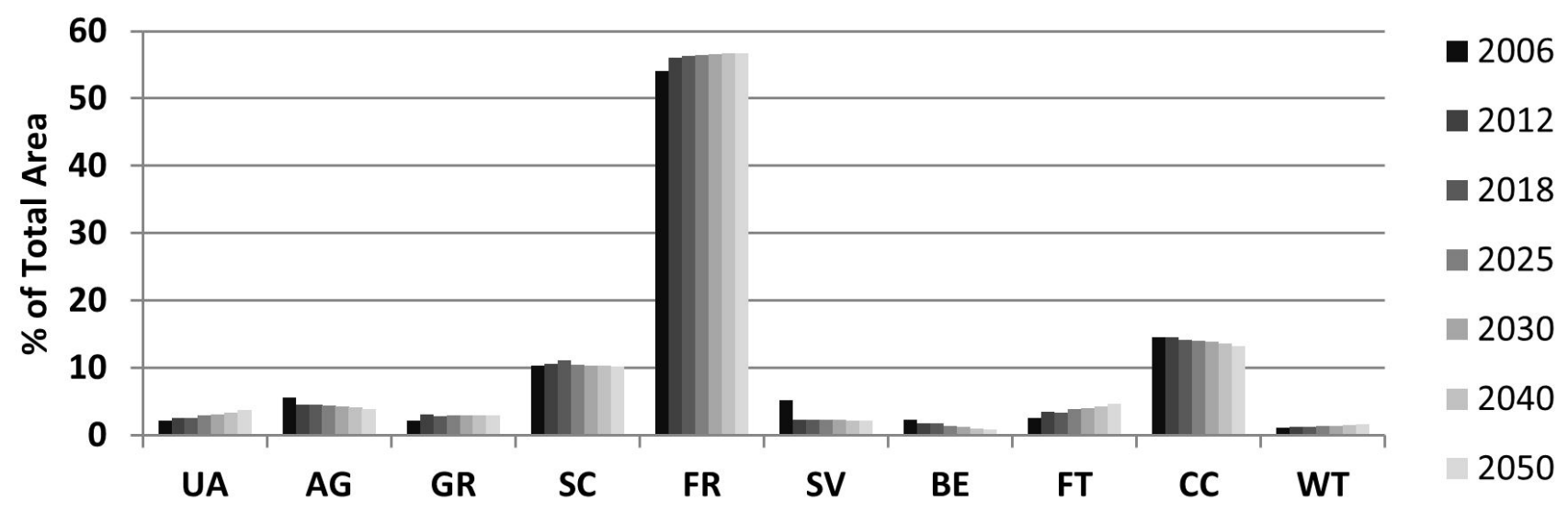

Fig. 4. Changes of LUCC classes from 2006 to 2050. 

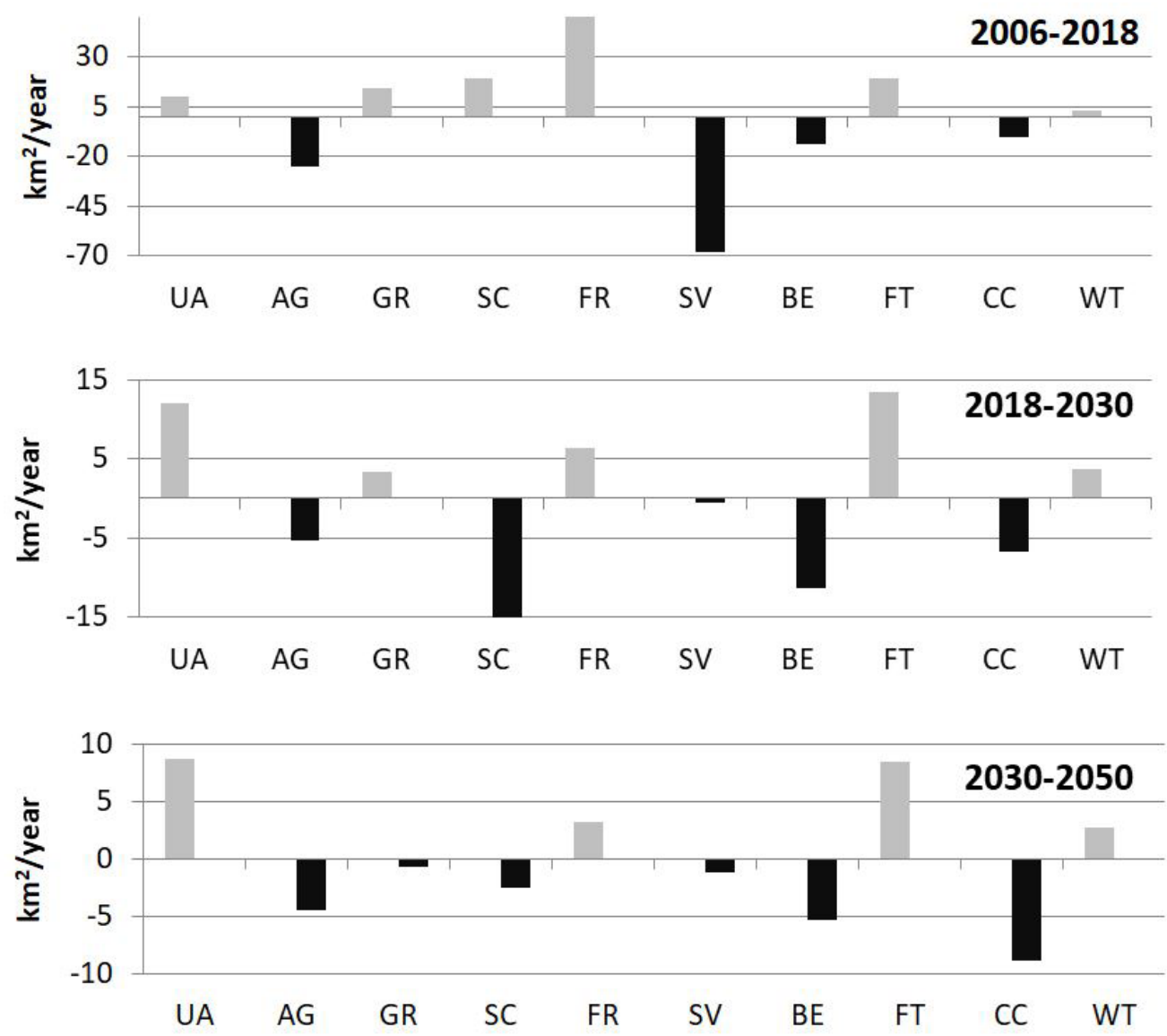

Fig. 5. Annual rates of gain/loss for each LUCC class in prediction periods.

Table 4.

AHP pairwise comparison matrix

\begin{tabular}{|c|c|c|c|c|c|c|c|c|c|c|c|}
\hline \multirow[t]{2}{*}{ Criteria } & Aspect & Elevation & $\begin{array}{l}\text { Land } \\
\text { Use }\end{array}$ & $\begin{array}{l}\text { Dist. to } \\
\text { Roads }\end{array}$ & $\begin{array}{l}\text { Dist.to } \\
\text { Wates }\end{array}$ & $\begin{array}{l}\text { Dist. to } \\
\text { Sett. }\end{array}$ & Slope & $\begin{array}{c}\text { Natural } \\
\text { Disasters }\end{array}$ & $\begin{array}{l}\text { Power } \\
\text { Lines }\end{array}$ & Railways & \multirow[t]{2}{*}{ W } \\
\hline & (AS) & (EL) & $(\mathrm{LU})$ & (DtR) & $(D t W)$ & $(\mathrm{DtS})$ & $(\mathrm{SL})$ & (ND) & $(\mathrm{PL})$ & (RL) & \\
\hline Aspect & 1 & 1.6 & 0.3 & 4 & 0.9 & 4 & 3 & 3 & 4 & 3 & 0.139 \\
\hline Elevation & & 1 & 0.3 & 2 & 0.9 & 2 & 1.9 & 2 & 2.7 & 2 & 0.094 \\
\hline Land Use & & & 1 & 9 & 2.5 & 9 & 9 & 8.2 & 9 & 8.2 & 0.366 \\
\hline $\begin{array}{l}\text { Dist. to } \\
\text { Roads }\end{array}$ & & & & 1 & 0.2 & 1.2 & 1 & 1 & 0.9 & 1 & 0.041 \\
\hline $\begin{array}{l}\text { Dist. to } \\
\text { Water }\end{array}$ & & & & & 1 & 4.8 & 3.2 & 3 & 4 & 3 & 0.149 \\
\hline Dist. to Sett. & & & & & & 1 & 0.8 & 0.8 & 1 & 1.2 & 0.039 \\
\hline Slope & & & & & & & 1 & 1 & 1.6 & 1 & 0.046 \\
\hline N. Disasters & & & & & & & & 1 & 1.2 & 1 & 0.045 \\
\hline Power lines & & & & & & & & & 1 & 1.3 & 0.039 \\
\hline Railways & & & & & & & & & & 1 & 0.042 \\
\hline
\end{tabular}

Total Suitability (TS) value refers to the result criteria were classified from 1 to 9, the TS map map in which all criteria contribute to the total must have a suitability value from maximum 9 suitability with their weight. Because all the to minimum 1 and is calculated as follows,

Total Suitability (TS)

$$
\begin{aligned}
& =\sum_{i=1}^{n}=w i . r i \\
& =W_{A S .} A S+W_{E L .} E L+W_{L U .} L U+W_{D t R .} D t R+W_{D t W .} D t W+W_{D t S .} D t S+W_{S L .} S L \\
& +W_{N D .} N D+W_{P L .} P L+W_{R L .} R L
\end{aligned}
$$

270 

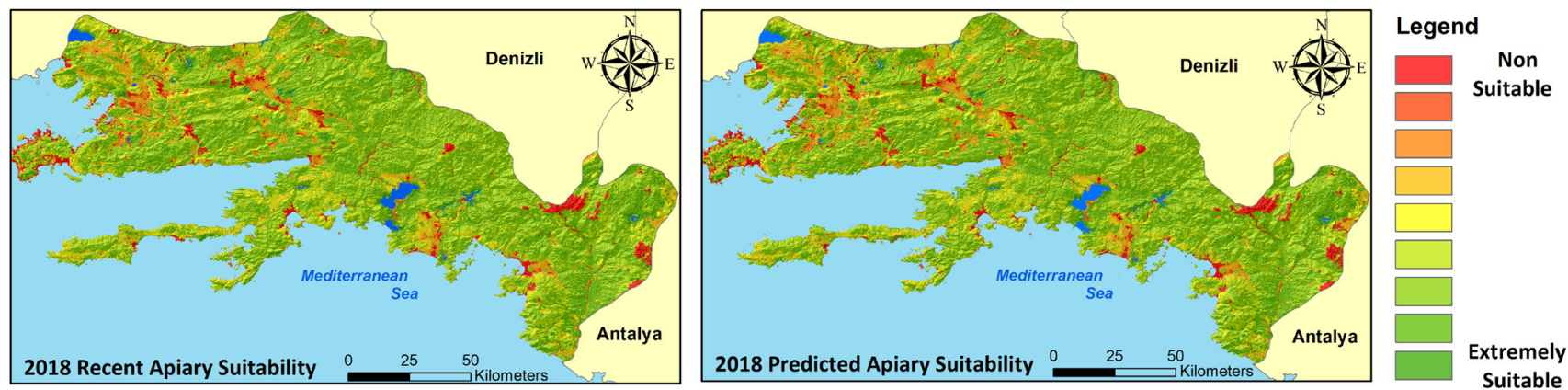

Fig. 6. Recent 2018 and predicted 2018 beekeeping suitability maps.

For the purpose of testing the model, the predicted 2018 LUCC map replaced the recent 2018 LUCC map to generate both the recent and predicted 2018 beekeeping suitability maps. In the Total Suitability formula, the Land Use (LU) criteria were changed from recent to predicted, and the generated recent 2018 and predicted 2018 beekeeping suitability maps are given in Fig. 6.

The suitability maps indicate that there is a agreement between the recent and predicted 2018 suitability maps. While highly suitable areas were calculated as $55.61 \%$ and $55.87 \%$ of the study area, non-suitable areas were calculated as $5.85 \%$ and $5.96 \%$ in the recent and predicted 2018 suitability maps, respectively. The determined suitability values are quite close, which means that the 2018 beekeeping suitability map was predicted very accurately and that the established model could be used for the years 2025, 2030, 2040 and 2050. The similarity of the recent and predicted 2018 maps also indicates the reliability and applicability of the demonstrated CA-Markov model. Because the Land-Use criterion has a $37 \%$ weight, the suitability values were constituted by the land-use criterion and the LUCC changes have the highest effect on beekeeping suitability values. During the evaluation of the highly suitable areas, forests and grasslands mostly overlapped with highly suitable areas due to the pine honey production.

For the purpose of predicting future beekeeping suitability in Muğla, the predicted 2025, 2030, 2040 and 2050 LUCC maps were used in the AHP calculation instead of the 2018 LUCC map.
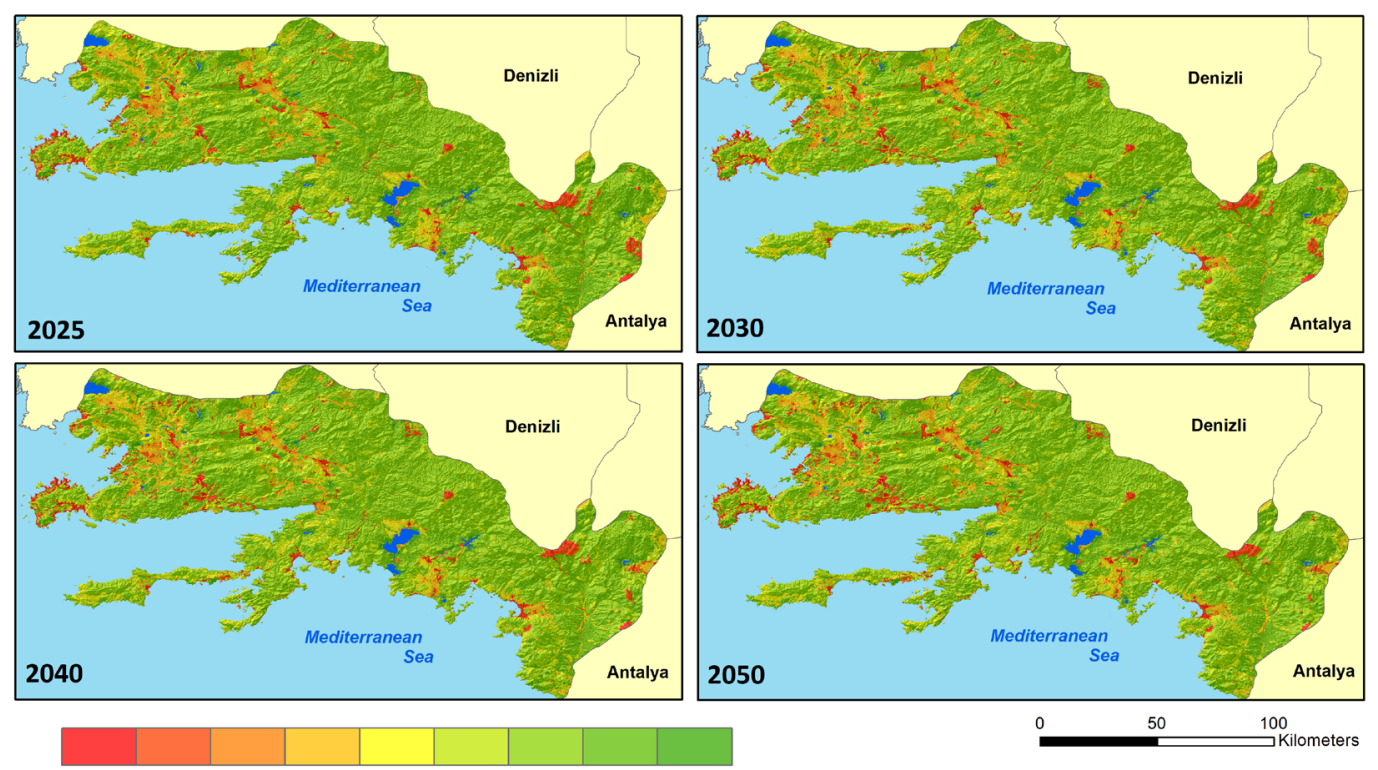

Non Suitable

Extremely Suitable

Fig. 7. Predicted 2025, 2030, 2040 and 2050 beekeeping suitability maps. 
Table 5.

Area changes of suitability classes $\left(\mathrm{km}^{2}\right)$

\begin{tabular}{cccccc}
\hline Suitability Classes & 2018 & 2025 & 2030 & 2040 & 2050 \\
\hline 1 (Non-Suitable) & 466.2 & 490.5 & 499.76 & 519.9 & 545.0 \\
2 & 164.4 & 163.1 & 163.03 & 165.1 & 168.1 \\
3 & 115.5 & 113.5 & 112.12 & 110.6 & 108.9 \\
4 & 896.0 & 904.0 & 908.16 & 917.3 & 926.4 \\
5 (Moderately & 1066.8 & 1047.4 & 1050.56 & 1055.1 & 1058.2 \\
Suitable) & 2951.6 & 2918.2 & 2916.42 & 2909.8 & 2903.6 \\
6 & 4851.7 & 4853.9 & 4844.27 & 4825.9 & 4805.7 \\
7 & 2003.3 & 2012.5 & 2008.93 & 1999.9 & 1989.1 \\
8 & 236.5 & 248.9 & 249.20 & 248.5 & 247.1 \\
9 (Extremely & & & & & \\
Suitable) & & & & & \\
\hline
\end{tabular}

Other criteria were accepted as stable because elevation, slope and aspect data could not change within thirty years. Although data for settlements, railways, roads, power lines and water resources could change, since the highest distance to these classes is important for beekeeping, the buffer zones of the nine classes could still include the changes and be accepted as stable. This can be a disadvantage for future prediction, however, as the LUCC maps also include urban expansion. Thus, a highly weighted land-use map could overcome this disadvantage for future beekeeping suitability. The future beekeeping suitability maps are given in Fig. 7. The predicted suitability maps indicate that urban expansion and deforestation considerably increase in unsuitable areas from 2018 to 2050. Urban areas and fruit tree areas will be especially increased by $162.52 \mathrm{~km}^{2}$ and 169.33 $\mathrm{km}^{2}$, respectively, by the end of 2050, and considering the transition probabilities, forests, complex cultivation areas and grasslands will gradually join urban and fruit tree areas. Thus, expansion of tourism-related urban areas and olive tree-related fruit tree area are detected as the greatest threats for beekeeping in Muğla.

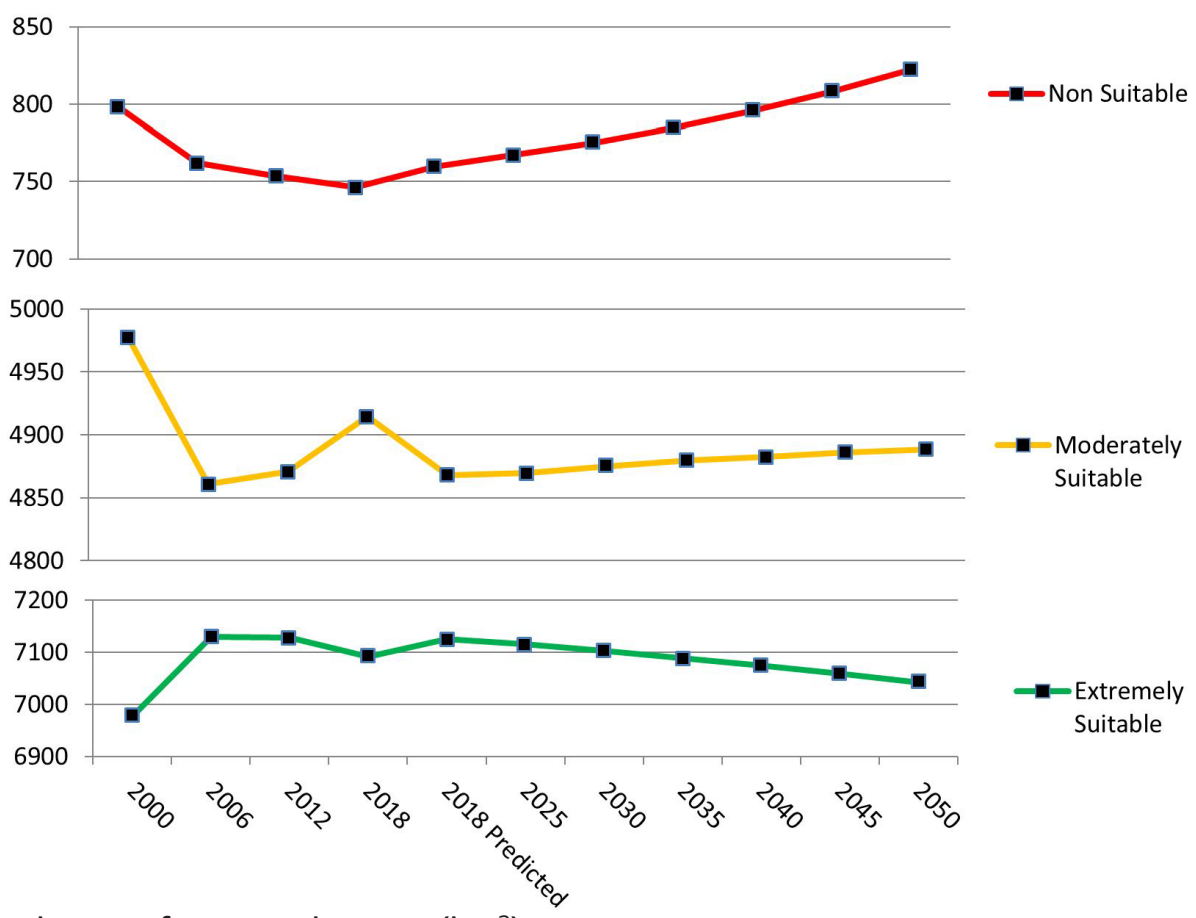

Fig. 8. Suitability clusters for area changes $\left(\mathrm{km}^{2}\right)$. 


\section{Ј. APPC. SCLI. VOL. 64 N NO. 2 2020}

As a result, non-suitable beekeeping areas (1) will increase by $79 \mathrm{~km}^{2}$ and extremely suitable beekeeping areas (9) will decrease by $10.55 \mathrm{~km}^{2}$ by the end of 2050. The changes of beekeeping suitability classes in $\mathrm{km}^{2}$ are given in Tab. 5 . In the suitability analysis, nine suitability classes were clustered into three classes as highly suitable $(9,8,7)$, moderately suitable $(6,5,4)$ and non-suitable $(3,2,1)$. The area comparison of suitability classes shows that while highly suitable areas are decreasing, non-suitable areas are increasing. The non-suitable areas will increase by $76 \mathrm{~km}^{2}$ and the highly suitable areas will decrease by $50 \mathrm{~km}^{2}$ by the end of 2050 , as can be seen in Fig. 8.

\section{DISCUSSION}

In this study, 2025, 2030, 2040 and 2050 LUCC maps were predicted successfully with the CA-Markov model for generating future beekeeping suitability maps. The CA-Markov model and Multi Criteria Decision Analysis integration approach for future beekeeping suitability assessment was first introduced in this study. Future beekeeping activities and suitability have a strong relationship with land-use changes and human-related factors. Thus, predicting the future LUCC maps will provide valuable information about future beekeeping activities in the study area. Moreover, this study has vital importance in the determination of honey bee conservation areas for protecting natural resources by considering future trends in beekeeping activities and land-cover changes. Recent studies on beekeeping suitability (Maris et al., 2008; Estaque \& Murayama, 2010; Amiri \& Shariff, 2012; Abou-Shaara et al., 2013; Camargo et al., 2014; Zoccali et al., 2017) included only suitability analysis via Geographical Information Systems and MCDA techniques by considering criteria related to beekeeping activities. However, future suitability prediction is as important as recent suitability analysis due to the rapid changes in land cover discussed in this study.

The area-change results reveal an increase in urban areas and decreases in agriculture, complex cultivation lands and grasslands. From 2006 to 2050, tourism-related urban expansion will destroy natural areas, because the transition probabilities indicate that a large amount of grasslands, sclerophyll, complex cultivation areas and forests would be transformed into urban areas. Because beekeepers are located in the mentioned areas, prevention procedures must be specified to protect natural areas from now on. Moreover, if sustainable development and environmental resource management policies are not constituted for evaluating the recent land-use change trends, this status of land-use will start to threaten beekeeping activities seriously in the near future. Although forests will gradually be increased from 2018 to 2050, the Muğla province has the highest forest fire risk potential in Turkey and destroyed forests will cause productivity to decrease rapidly and even the loss of bee colonies. Thus, simulated land cover and beekeeping suitability maps can be accepted as an early warning system that predicts Muğla's beekeeping future status ahead of time.

The acquired information is valuable for other beekeeping areas in Turkey and can be accepted as a conceptual model for future beekeeping assessment. The results can serve as a guide to local authorities for land-use management strategies to ensure the balance between urban development and environmental conservation for beekeeping.

\section{REFERENCES}

Abou-Shaara, H.F., Al-Ghamdi, A.A., \& Mohamed A.A. (2013). A Suitability Map for Keeping Honey Bees Under Harsh Environmental Conditions Using Geographical Information System. World Applied Sciences Journal, 22, 1099 -1105. DOl: 10.5829/idosi. wasj.2013.22.08.7384

Agarwal, C., Green, G.M., Grove, J.M., Evans, T.P., Schweik, C.M. (2002). A review and assessment of landuse change models: dynamics of space, time, and human choice, Gen. Tech. Rep. NE-297, U.S. Department of Agriculture, Forest Service, Northeastern Research Station. Newtown Square, PA. p 61. 
Aizen, M.A., Garibaldi, L.A., Cunningham, S.A., \& Klein, A.M. (2009). How much does agriculture depend on pollinators? Lessons from long-term trends in crop production. Annals of Botany, 103(9), 1579-1588. DOl: $10.1093 / a o b / m c p 076$

Amiri, F., \& Shariff, M.A. (2012). Application of geographic information systems in land use suitability evaluation for beekeeping: A case study of Vahregan watershed (Iran). African Journal of Agricultural Research, 71), 89-97. D01:10.5897/AJAR10.1037 Baker, W.L. (1989). A review of models of landscape change. Landscape Ecology, 2, 111-133

Camargo, S.C., Garcia, R.C., Feiden, A., Vasconcelos, E.S., Pires., B.G. ... Pereira, D., I. (2014).Implementation of a geographic information system (GIS) for the planning of beekeeping in the west region of Paraná. Annals of the Brazilian Academy of Sciences, 86(2), 955-971.http://dx.doi.org/10.1590/00013765201420130278

Damián, G.C. (2016). GIS-based optimal localisation of beekeeping in rural Kenya Master degree thesis, 30/ credits in Master in Geographical Information Sciences Department of Physical Ceography and Ecosystems Science, Lund University

Eastman, J.R. (2009). IDRISI guide to GIS and image processing Accessed in IDRISI Selva 17 (pp. 182185). Worcester, MA: Clark University.

Estoque, R.C., \& Murayama, Y. (2010). Suitability Analysis for Beekeeping Sites in La Union, Philippines, Using GIS and Multi-Criteria Evaluation Techniques. Research Journal of Applied Sciences, 5(3), 242-253. DOl: 10.3923/rjasci.2010.242.253

Estoque, R.C., \& Murayama, Y. (2011). Suitability Analysis for Beekeeping Sites Integrating GIS \& MCE Techniques. Spatial Analysis and Modeling in Geographical Transformation Process. 978-94-0070670-5. Springer Netherlands.

Fernandez, P., Roque, N., \& Anjos, O. (2016). Spatial multicriteria decision analysis to potential beekeeping assessment. Case study: Montesinho Natural Park (Portugal). In: Sarjakoski, T, Santos, M.Y., Sarja- koski, L.T. (Eds.), 19th AGILE International Conference on Geographic Information Science - Geospatial Data in a Changing World, Helsinki, Finland.

Gagniuc, P.A. (2017). Markov Chains: From Theory to Implementation and Experimentation. USA, NJ: John Wiley \& Sons. pp. 1-235. ISBN 978-1-119-387558.

Goulson, D., Nicholls, E., Botías, C., \& Rotheray, E.L. (2015). Bee declines driven by combined stress from parasites, pesticides, and lack of flowers. Science, 3476229),1255957. DOl: 10.1126/science.1255957

Guan, D., Li, H., Inohae, T., Su, W., Nagaie, T., Hokao, K. (2011). Modeling urban land use change by the integration of cellular automaton and Markov model. Ecological Modelling, 222, 3761-3772. https://doi. org/10.1016/j.ecolmodel.2011.09.009

Halmy, M.W., Gessler, P.E., Hicke, J.A., \& Salem, B.B. (2015). Land use/land cover change detection and prediction in the north-western coastal desert of Egypt using Markov-CA. Applied Geography, 63, 101112. https://doi.org/10.1016/j.apgeog.2015.06.015

He, C.Y., Okada, N., Zhang, Q.F., Shi, P.., Li, J.G. (2008), Modelling dynamic urban expansion processes incorporating a potential model with cellular automata. Landscape Urban Planning, 86, 79-91. https://doi. org/10.1016/j.landurbplan.2007.12.010

Huang, W., Liu, H., Luan, Q., Jiang, Q., Liu, J., Liu, H. (2008). Detection and prediction of land use change in Beijing based on remote sensing and GIS. The International Archives of the Photogrammetry, Remote Sensing and Spatial Information Sciences, XXXVII, 75-82.

Lambin, E.F. (1997). Modeling and Monitoring LandCover Change Processes in Tropical Regions. Progress in Physical Geography, 27, 375-393. https:// doi.org/10.1177/030913339702100303

Maris, N., Mansor, S., \& Shafri, H. (2008). Apicultural Site Zonation Using CIS and MultiCriteria Decision Analysis. Journal of Tropical Agricultural Science, 37(2), 147-162. 


\section{ง. APRC. SCLI. VOL. 64 NO. 2 2020}

Miguel, S., Pukkala, T., \& Yeşil, A. (2014). Integrating pine honeydew honey production into forest management optimization. European Journal of Forest Research, 133 (3), 423-432. DOl: 10.1007/s10342013-0774-2

Mondal, S., Sharma, N., Garg, P.K., \& Kappas, M. (2016). Statistical independence test and validation of CA Markov land use land cover (LULC) prediction results. The Egyptian Journal of Remote Sensing and Space Sciences, 19, 259-272. https://doi.org/10.1016/j. ejrs.2016.08.001

Muller, M.R., \& Middleton, J. (1994). A Markov model of land-use change dynamics in the Niagara Region, Ontario, Canada. Landscape Ecology, 9, 151-157.

Oldroyd, P.B., \& Nanork, P. (2009). Conservation of Asian honey-bees- Apidologie Bee Conservation, 40, 296-312. https://doi.org/10.1051/apido/2009021

Otto, C.R.V., Roth, C.L., Carlson, B.L., \& Smart, M.D. (2016). Land-use change reduces habitat suitability for supporting managed honey bee colonies in the Northern Great Plains. PNAS, 173(37), 1043010435. https://doi.org/10.1073/pnas.1603481113

Parker, D.C., Manson, S.M., Janssen, M.A., Hoffmann, M.J., Deadman, P. (2003). Multi agent systems for the simulation of land-use and land-cover change: a review, Annals of the Association of American Geographers, 93, 314-337. https://doi.org/10.1111/14678306.9302004

Pontius, J.R.G., \& Malanson, J. (2005). Comparison of the structure and accuracy of two land change models. International Journal of Geographical Information Sciences, 19(2), 243-265. https://doi.org/10. 1080/13658810410001713434

Spivak, M., Mader, E., Vaughan, M., \& Euliss, N.H. (2011). The plight of the bees. Environmenta/Science Technology, 45(1), 34-38. https://doi.org/10.1021/ es101468w

Subedi, P., Subedi, K., \& Thapa, B., (2013). Application of a Hybrid Cellular Automaton - Markov (CA-Mark- ov) Model in Land-Use Change Prediction: A Case Study of Saddle Creek Drainage Basin, Florida. Applied Ecology and Environmental Sciences, 1(6), 126132. DOI: 10.12691/aees-7-6-5

Saaty, T.L. (1977). A scaling method for priorities in hierarchical structures. Journal of Mathematical Psychology, 15, 234-281.

Saaty, T.L. (1980). The analytical hierarchy process. New York: Wiley.

Saaty, T.L. (1994). Fundamentals of Decision Making and Priority Theory With The Analytical Hierarchy Process, RWS Publ. Pittsburg, 69-84.

Saaty, T.L. (2001). Decision Making with Dependence and Feedback: The Analytic Network Process, 2nd edition, PRWS Publications, Pittsburgh PA.

Saaty, T.L., \& Vargas, LG. (1991). Prediction, Projection and Forecasting. Kluwer Academic Publishers, Dordrecht, 25.

Sala, O.E., Chapin, F.S., Armesto, J.J, Berlow, E., Bloomfield, J., Dirzo, R.,... Wall, D. H. (2000). Global biodiversity scenarios for the year 2100. Science, 2875459), 1770-1774. DOl: 10.1126/science.287.5459.1770

Sklar, F.H., \& Costanza, R. (1991). The development of dynamic spatial models for landscape ecology: a review and prognosis. In M. G. Turner, \& R. H. Gardner (Eds.), Ecological studies: Vol. 82. Quantitative methods in landscape Ecology (pp. 239-288). Berlin: Springer.

Thomas, H., \& Laurence, H.M. (2006). Modeling and projecting land-use and land-cover changes with a cellular automaton in considering landscape trajectories: An improvement for simulation of plausible future states; EARSeL eProc. 5 63-76.

Wang, SQ., Zheng, XQ., \& Zang, XB. (2012). Accuracy assessments of land use change simulation based on Markov-cellular automata model. Procedia Environmental Sciences, 13, 1238 - 1245. https://doi. org/10.1016/j.proenv.2012.01.117 
Wu, F., (2002). Calibration of stochastic cellular automata: the application to rural-urban land conversions. International Journal of Geographical Information Sciences, 16, 795-818. https://doi. org/10.1080/13658810210157769

Vanbergen, A.J., \& the Insect Pollinators Initiative (2013). Threats to an ecosystem service: Pressures on pollinators. Frontiers in Ecology and the Environment, 11(5), 251-259. https://doi. org/10.1890/120126

Ye, B., \& Bai, Z. (2008). Simulating land use/cover changes of Nenjiang County based on CA-Markov model. International Federation for Information Processing Publications IFIP, 258, 321-330.
Zoccali, P., Malacrinò, A., Campolo, O., Laudani, F., Algeri, G.M., Giunti, G., ... Palmeri, V. (2017). A novel GISbased approach to assess beekeeping suitability of Mediterranean lands. Saudi Journal of Biological Sciences, 24(5), 1045-1050. https://doi.org/10.1016/j. sjbs.2017.01.062

URL1, Turkey Governmental Forest Statistics https:// www.ogm.gov.tr/lang/en/Pages

/Forests/Statisticallnfo.aspx (Accessed, 17.11.2018) 